\title{
The effect of etanercept and anakinra on experimental type 2 diabetes pathology in rats
}

\author{
Ozgur Ozdemir, Mehmet Burak Ates, Gokhan Akcakavak
}

University of Selcuk, Faculty of Veterinary Medicine, Department of Pathology, Konya, Turkey

Received February 6, 2021

Accepted November 9, 2021

\begin{abstract}
In this study, the effects of etanercept, anakinra, and their combination on streptozotocininduced type 2 diabetes in rats were pathologically evaluated. A total of 30 rats were separated into 5 groups as control (C), diabetes (D), diabetes + anakinra (DA), diabetes + etanercept (DE), and diabetes + anakinra + etanercept (DAE). Anakinra $(10 \mathrm{mg} / \mathrm{kg} /$ day, s.c.) and etanercept $(10 \mathrm{mg} / \mathrm{kg}$, twice weekly, s.c.) were administered to the DA and DE groups, respectively, and the DAE group received both anakinra and etanercept for 21 days. Histopathologically, pathological changes related to diabetes in internal organs occurred in the diabetes group, and there was a significant decrease (improvement) in these changes in the treatment groups $(P<0.05)$. There was no significant difference $(P>0.05)$ between the treatment groups, but some changes in the liver and kidneys were higher in the combined group which should be taken into account for longer use. Although there was no significant difference, etanercept was more effective on pancreatic lesion scores and anakinra was more effective on testicular changes. As a result, the single or combined use of IL-1 and TNF- $\alpha$ antagonists anakinra and etanercept were effective in the treatment of type 2 diabetes in rats without any toxic-pathological effect.
\end{abstract}

\section{Histopathology, IL-1, TNF-alpha}

Diabetes mellitus is a chronic metabolic disease characterized by a steady increase in blood sugar levels developed by the combined effects of genetic and environmental factors (Mirmiran et al. 2014). Diabetes occurs in two ways as a decrease in insulin production (Type 1 diabetes) and/or due to insulin resistance (Type 2 diabetes). Type 2 diabetes mellitus (T2DM) is a multifactorial disease that results from ineffective use of insulin by the body and causes chronic hyperglycaemia (Gopalakrishnan and Geetha 2017). T2DM, which represents $90 \%$ of diabetes mellitus cases, is qualified by hyperglycaemia and high circulating free fatty acids (Keane et al. 2017). In the event of chronic hyperglycaemia, some microvascular (nephropathy, neuropathy, and retinopathy) and macrovascular (coronary artery disease, peripheral artery disease) complications may take place in both types of diabetes (Chawla et al. 2016).

Glucose toxicity, which is an important feature of diabetes mellitus, leads to reactive oxygen species (ROS) production, which induces oxidative stress. Oxidative stress caused by hyperglycaemia is believed to augment the levels of pro-inflammatory proteins that stimulate many inflammatory cytokines that cause local and systemic inflammation (Wellen and Hotamisligil 2005). ROS production increases the production of tumour necrosis factor-alpha (TNF- $\alpha$ ), plasminogen activating inhibitor-1 (PAI-1), monocyte chemoattractant protein-1 (MCP-1), resistin and leptin, while decreasing the production of adiponectin (Trayhurn and Wood 2005).

Interleukin-6 (IL-6), interleukin-1 beta (IL-1 $\beta$ ), and TNF- $\alpha$ are important pro-inflammatory agents that cause inflammation in vital organs in the body in normal homeostasis (Donath and Shoelson 2011; Akash et al. 2013). TNF- $\alpha$ is mainly secreted from macrophages and can induce IL-6 and IL-1 $\beta$ expression as an inflammatory factor (Harford et al. 2011).

Address for correspondence:

Gokhan Akcakavak

Department of Veterinary Pathology

Faculty of Veterinary Medicine, Selcuk University

Konya, Turkey

Phone: +90 5549977046

E-mail: hdsht07@hotmail.com

http://actavet.vfu.cz/ 
In previous studies, it was reported that a high TNF- $\alpha$ level plays a role in the pathophysiology of insulin resistance and the development of T2DM (Swaroop et al. 2012).

The main sources of IL- $1 \beta$ are blood monocytes, tissue macrophages, and dendritic cells. Besides, B lymphocytes and NK cells also produce IL-1 $\beta$ (Kim et al. 2013). In cases of infection or injury, IL-1 $\beta$ induces the production of cytokines and chemokines from the endothelial, epithelial, and immunocomplex cells. Also, IL-1 $\beta$ can cause macrophage infiltration by acting on pancreatic islets (Ehses et al. 2007). IL-1 $\beta$ not only causes degenerative changes in $\beta$ cells and impaired insulin secretion, but also impairs insulin signalling transduction in target tissues (Maedler et al. 2009). High glucose and free fatty acid levels lead to increased IL-1 $\beta$ activity, activation of the NF-kB pathway, oxidative stress, mononuclear cell infiltration and activation, and the development of insulindependent disorders (Akash et al. 2013).

The use of IL-1 antagonists in T2DM has been reported to reduce systemic inflammation, hyperglycaemia, and $\beta$-cell dysfunction (Larsen et al. 2007). In a study conducted on diabetic rats with anakinra, one of the IL-1 antagonists, it was observed that inflammation and insulin resistance decreased and $\beta$-cell functions improved (Ehses et al. 2009). Similarly, it was emphasized that the use of etanercept, which is TNF- $\alpha$ antagonist in the treatment of T2DM, regulates inflammation and the release of adipokines reduces systemic inflammation and glucose concentration to normal and increases adiponectin expression (Dominguez et al. 2005; Bonilla et al. 2007; Stanley et al. 2011). Thus, hindering such disorders by specifically antagonizing these proinflammatory cytokines is considered a good treatment strategy. In our study, we aimed to investigate the pathological effects of antagonizing IL- $1 \beta$ and TNF- $\alpha$ with anakinra and etanercept both individually and in combination in rats with T2DM.

\section{Materials and Methods}

Animals

The research trials were carried out on 30 Wistar Albino rats, 6-10 weeks old and 200-250 g live weight. The experimental animals were given feed and water ad libitum. The ration composition for the healthy control group - dry matter: $89 \%$, crude protein: $21 \%$, cellulose: at most $5 \%$, ash: at most $10 \%, \mathrm{Ca}: 2 \%, \mathrm{P}: 1 \%, \mathrm{NaCl}: 0.5 \%$, ME: $2850 \mathrm{kcal} / \mathrm{kg}$ determined. Animals were housed under $12 / 12 \mathrm{~h} \mathrm{light} /$ dark regime, $22 \pm 2{ }^{\circ} \mathrm{C}$, and $55 \pm 5 \%$ humidity. The compliance of the study with ethical principles was approved by the Selcuk University Faculty of Veterinary Medicine Experimental Animal Production and Research Centre Ethics Committee (No: 2020/47).

Development of experimental T2DM model and experimental design

In the study, the experimental T2DM model was made according to the method suggested by Srinivasan et al. (2005). Accordingly, animals were administered a high-fat diet (HFD) in which 58\% of the metabolic energy was comprised of animal fat (Table 1). After feeding on this diet for 2 weeks, $35 \mathrm{mg} / \mathrm{kg}$ Streptozotocin (STZ, $\geq 98 \%$, Sigma-Aldrich Co., USA, dissolved in citrate buffer [ $\mathrm{pH} 4.5,20 \mathrm{mg} / \mathrm{ml}]$ ) was administered intraperitoneally (i.p.). Animals with a fasting blood glucose concentration higher than $300 \mathrm{mg} / \mathrm{dl}$ seven days after this application

Table 1. Components of a high fat diet.

\begin{tabular}{lr}
\hline Feed Components & \multicolumn{1}{c}{$\%$} \\
\hline Vegetable oil & 3.00 \\
Animal fat & 37.00 \\
Yellow corn & 30.50 \\
Casein (dried) & 20.00 \\
Soybean meal (48\%) & 4.50 \\
Dicalcium phosphate & 1.70 \\
Dl-Methionine & 0.20 \\
Limestone & 1.60 \\
Salt & 0.50 \\
Vitamin-mineral mix & 1.00 \\
\hline
\end{tabular}
were considered Type 2 diabetic. The rats were fed ad libitum HFD diet during a total trial period of 21 days. The DA group was given anakinra $(10 \mathrm{mg} / \mathrm{kg} / \mathrm{day}$, subcutaneously, s.c.) (Ehses et al. 2009) while the DE group was given etanercept $(10 \mathrm{mg} / \mathrm{kg}$, twice weekly, s.c.) (Dogrul et al. 2011) for 21 days after the development of diabetes. In addition, the DAE group was given a combination treatment of anakinra $(10 \mathrm{mg} / \mathrm{kg} /$ day, s.c. $)$ and etanercept $(10 \mathrm{mg} / \mathrm{kg}$, s.c., twice a week) for 21 days. At the end of the trial period, euthanasia was performed by cervical dislocation method under Na-thiopental anaesthesia $(40 \mathrm{mg} / \mathrm{kg}$, i.p.).

\section{Histopathological examination}

After the rats were euthanized, their macroscopic findings were recorded by systemic necropsies. Samples were taken from the organs for histopathological examination and fixated in $10 \%$ buffered formol. After routine tissue processing procedure, paraffin blocks were obtained and sections with a thickness of 
5 microns were taken. All sections were stained with haematoxylin-eosin $(\mathrm{HE})$. Besides, pancreases were stained with aldehyde fuchsin (AF) (Luna 1968). All preparations were evaluated under a light microscope (Olympus BX51, Tokyo, Japan). Lesions in the organs were scored as mild (1), moderate (2), and severe (3) (Vard1 et al. 2005; Ozdemir et al. 2009). Scoring of AF staining on the pancreas; full staining (4), three staining in four (3), two staining in four (2), and one dyeing in four (1) in the form was applied.

\section{Statistical analysis}

Histopathological scores obtained from the study were subjected to normal distribution test with SPSS 22.0 (SPSS, Inc., Chicago, IL, USA) statistical program. Normally distributed data and parametric data were evaluated by One-Way ANOVA post hoc Duncan test and lettered. Since it did not show a normal distribution, it was evaluated with Mann-Whitney U test. $P<0.05$ was considered significant.

\section{Results}

\section{Macroscopic findings}

On macroscopic examination, the kidneys of the D group animals were more swollen and paler than the $\mathrm{C}$ group. When compared to the $\mathrm{C}$ group, bodyweight decreased in the D, DA, DE, and DAE groups $(P<0.05$, Fig. 1$)$. Relative kidney weight increased in the D, DA and DAE groups compared to the $\mathrm{C}$ group $(P<0.05)$. However, there was no significant difference between the DE group and the $\mathrm{C}$ and $\mathrm{D}$ groups $(P>0.05$, Fig. 2).

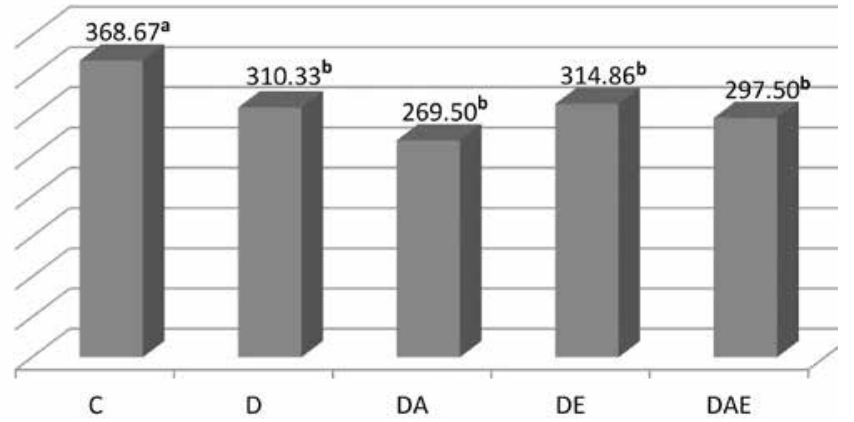

Fig. 1. Body weight (g) at the end of the study. C - control; D - diabetes; DA - diabetes + anakinra; DE - diabetes + etanercept; DAE - diabetes + anakinra + etanercept

${ }^{\mathrm{a}, \mathrm{b}}$ Values without common superscripts are significantly different $(P<0.05)$.

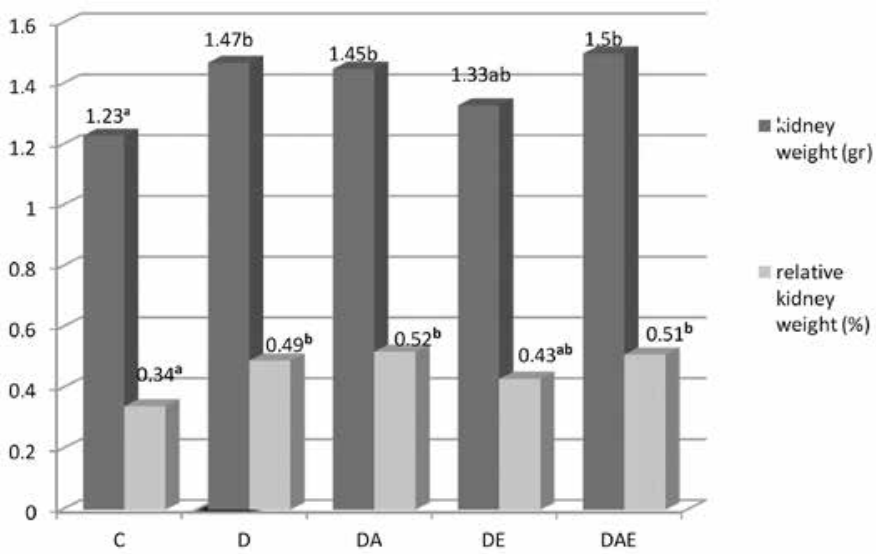

Fig. 2. Kidney and relative kidney weight. C - control; D - diabetes; DA - diabetes + anakinra; DE - diabetes + etanercept; DAE - diabetes + anakinra + etanercept

A, B, a, b Values without common superscripts are significantly different $(P<0.05)$. 


\section{Microscopic findings}

The histopathological changes in the organs of the experimental T2DM model created with a high-fat diet and streptozotocin of the IL-1 antagonist anakinra and the TNF- $\alpha$ antagonist etanercept are presented in Tables 3 and 4.

\section{Pancreas}

Pancreases of the rats in the control group were observed as Langerhans islets dispersed within the normal exocrine and acinar architecture (Plate XIII, Figs 3.1-6), and mostly basophilic beta cells and less acidophilic alpha cells were observed in these islets. In the D group, besides the shrinkage of Langerhans islets, degeneration, and decrease in numbers (necrosis and apoptosis) were also detected in basophilic cells (Fig. 3.7). Also, hydropic degeneration was detected in the acinar cells in the exocrine pancreas. Although milder scores were observed in the treatment groups (DA, DE, DAE) compared to the D group (Figs $3.3-5$ and $8-10)$, the scores were similar to the healthy control group $(P>0.05$, Table 2$)$. Although AF staining scores for determining the density of $\beta$-cells in Langerhans islets decreased considerably in the $\mathrm{D}$ group (Fig. 3.2), the treatment groups showed an increase when compared to the $\mathrm{D}$ group $(P<0.05$, Table 3$)$.

Table 2. Histopathological examination.

\begin{tabular}{|c|c|c|c|c|c|c|c|}
\hline Organ & Lesions & $C(n: 6)$ & D (n:6) & DA (n:6) & DE (n:6) & DAE (n:6) & $P$ value \\
\hline Pancreas & $\begin{array}{l}\text { Degeneration } \\
\text { and necrosis } \\
\text { in } \beta \text {-cells }\end{array}$ & $0.58 \pm 0.08^{\mathrm{a}}$ & $1.33 \pm 0.27^{\mathrm{b}}$ & $0.83 \pm 0.10^{\mathrm{a}}$ & $0.83 \pm 0.10^{\mathrm{a}}$ & $0.83 \pm 0.10^{\mathrm{a}}$ & $<0.05$ \\
\hline \multirow{3}{*}{ Liver } & $\begin{array}{l}\text { Hydropic } \\
\text { degeneration } \\
\text { in hepatocytes }\end{array}$ & $0.17 \pm 0.11^{\mathrm{a}}$ & $1.33 \pm 0.11^{\mathrm{c}}$ & $0.83 \pm 0.11^{\mathrm{b}}$ & $0.83 \pm 0.11^{b}$ & $1.00 \pm 0.13^{\mathrm{b}}$ & $=0.00$ \\
\hline & Fatty change & $0.00 \pm 0.00^{\mathrm{a}}$ & $0.33 \pm 0.21^{\mathrm{b}}$ & $0.00 \pm 0.00^{\mathrm{a}}$ & $0.00 \pm 0.00^{\mathrm{a}}$ & $0.00 \pm 0.00^{\mathrm{a}}$ & $>0.05$ \\
\hline & $\begin{array}{l}\text { MNC infiltration } \\
\text { in the portal area }\end{array}$ & $0.00 \pm 0.00^{\mathrm{a}}$ & $0.42 \pm 0.20^{\mathrm{b}}$ & $0.08 \pm 0.08^{\mathrm{a}}$ & $0.00 \pm 0.00^{\mathrm{a}}$ & $0.08 \pm 0.08^{a}$ & $>0.05$ \\
\hline \multirow{4}{*}{ Kidney } & $\begin{array}{l}\text { Hydropic } \\
\text { degeneration } \\
\text { in tubulus }\end{array}$ & $0.58 \pm 0.08^{\mathrm{a}}$ & $1.33 \pm 0.28^{b}$ & $0.83 \pm 0.11^{\mathrm{a}}$ & $0.83 \pm 0.11^{\mathrm{a}}$ & $0.83 \pm 0.11^{\mathrm{a}}$ & $<0.05$ \\
\hline & $\begin{array}{l}\text { Expansion in the } \\
\text { Bowman's space }\end{array}$ & $0.08 \pm 0.08^{\mathrm{a}}$ & $0.92 \pm 0.24^{b}$ & $0.75 \pm 0.28^{b}$ & $1.08 \pm 0.15^{\mathrm{b}}$ & $0.75 \pm 0.11^{\mathrm{b}}$ & $<0.05$ \\
\hline & $\begin{array}{l}\text { Interstitial MNC } \\
\text { infiltration }\end{array}$ & $0.00 \pm 0.00^{\mathrm{a}}$ & $0.50 \pm 0.22^{\mathrm{a}}$ & $0.83 \pm 0.83^{a}$ & $1.17 \pm 0.79^{a}$ & $0.00 \pm 0.00^{\mathrm{a}}$ & $>0.05$ \\
\hline & Hyaline casts & $0.58 \pm 0.08^{\mathrm{a}}$ & $1.25 \pm 0.17^{\mathrm{b}}$ & $0.75 \pm 0.17^{\mathrm{a}}$ & $0.75 \pm 0.11^{\mathrm{a}}$ & $1.25 \pm 0.21^{\mathrm{b}}$ & $<0.05$ \\
\hline Testis & $\begin{array}{l}\text { Hydropic } \\
\text { degeneration } \\
\text { in tubulus }\end{array}$ & $1.00 \pm 0.00^{\mathrm{a}}$ & $2.50 \pm 0.22^{\mathrm{c}}$ & $1.67 \pm 0.21^{\mathrm{b}}$ & $1.83 \pm 0.17^{b}$ & $1.83 \pm 0.31^{\mathrm{b}}$ & $<0.01$ \\
\hline
\end{tabular}

a, b, c different superscripts within a row denote significance $(P<0.05)$. C - control; D - diabetes; DA - diabetes + anakinra; DE - diabetes + etanercept; DAE - diabetes + anakinra + etanercept

\section{Liver}

The histological appearance of the liver was found to be normal in the control group rats (Plate XIII, Fig. 3.11). In group D, pale colour was noted due to hydropic and/or vacuolar degeneration in hepatocytes. Besides, some hepatocytes showed stages of necrosis (pyknosis, karyorrhexis, karyolysis). Dissociation in remark cords and enlargement in sinusoids were determined (Fig. 3.12). Fat vacuoles were detected in some hepatocytes. 
Table 3. Beta-cell density determined by aldehyde fuchsin staining.

\begin{tabular}{lc}
\hline Pancreas & Aldehyde fuchsin scores \\
\hline C & $4.00 \pm 0.00^{\mathrm{a}}$ \\
$\mathrm{D}$ & $1.00 \pm 0.22^{\mathrm{c}}$ \\
$\mathrm{DA}$ & $1.83 \pm 0.21^{\mathrm{b}}$ \\
$\mathrm{DE}$ & $2.00 \pm 0.26^{\mathrm{b}}$ \\
DAE & $1.83 \pm 0.21^{\mathrm{b}}$ \\
\hline
\end{tabular}

a, b, c Different superscripts between groups indicate significance $(P<0.05)$. $\mathrm{C}$ - control; $\mathrm{D}$ - diabetes; DA - diabetes + anakinra; $\mathrm{DE}$ - diabetes + etanercept; DAE - diabetes + anakinra + etanercept

Also, mononuclear cell infiltrations, mostly composed of histiocytes and lymphocytes, were detected in the portal area. Although there are signs of hydropic degeneration in hepatocytes in the treatment groups (DA, DE, DAE), it was determined that these changes decreased significantly compared to the D group $(P<0.05$, Table 2, Figs 3.12-15).

\section{Kidney}

The kidneys of the control group rats had a normal tubular and glomerular structure (Plate XIII, Fig. 3.16). Hydropic degeneration and pycnotic nuclei were found in the tubular epithelium in the $\mathrm{D}$ group. Hyaline casts in the tubular lumen and mononuclear cell infiltration in the interstitial tissue were found, all of the mild severity. Tubulous basement membranes were observed to be normal. Although hydropic degeneration in the tubular epithelium decreased in the treatment groups compared to the diabetes group, it was found that there was no significant difference in other findings (Table 2). It was observed that the enlargement in the Bowman's space in group D did not decrease in the therapy groups. In addition, all cases were examined in terms of mesangial hypertrophy, glomerulosclerosis, and thickening of the basement membrane. However, no significant difference was found between groups $(P>0.05$, Figs 3.17-20).

\section{Testis}

A normal testicular appearance was detected in the control group. In the D group, a decrease in the germinative epithelium of the tubules seminiferous contortus (TSC) due to degeneration and necrosis was detected. Although oedema and thickening in some vessel walls, mononuclear cell infiltration in the interstitial tissue, and giant cell formations were seen, it was observed that they did not make a significant difference $(P>0.05)$. In the treatment groups, it was determined that the pathological findings observed in the TSC cells decreased $(P<0.05)$.

Table 4. Organ scores according to importance of histopathological findings within the group.

\begin{tabular}{lrrrrc}
\hline & C & D & DA & DE & DAE \\
\hline Pancreas & 1 & 2 & 1 & 1 & 1 \\
Liver & 3 & 7 & 4 & 4 & 4 \\
Kidney & 4 & 7 & 5 & 5 & 6 \\
Spleen & 3 & 5 & 3 & 3 & 3.5 \\
Testes & 1 & 3 & 2 & 2 & 2 \\
\hline Total scores & 12 & 24 & 15 & 15 & 15.5 \\
\hline$*) \%$ & 0 & +100 & +25 & +25 & +29 \\
\hline
\end{tabular}

Histopathological findings in the organs within the group were scored according to statistical significance in Table 2 and the total score for each organ was determined (scores; a: 1, b: 2, c: 3, d: 4, e: 5) and the total score of the group was determined.) (*) Increase in lesion scores compared to control group $(+)$. In other words, while $75 \%$ improvement was determined in individual treatments, $71 \%$ improvement was determined in combined application. C - control; D - diabetes; DA - diabetes + anakinra; DE - diabetes + etanercept; DAE - diabetes + anakinra + etanercept
Although there was no significant difference, it was observed that etanercept was more effective on pancreatic lesion scores and anakinra was more effective on testicular changes. Considering the organ scores according to the importance of the histopathological findings within the group (Table 4), 75\% improvement was detected in individual treatments, and $71 \%$ improvement was detected in the combined application.

\section{Discussion}

Normally, inflammation is considered a beneficial reaction to the host; irregular, excessive, or prolonged inflammatory responses may lead to the development of acute 
or chronic inflammatory diseases by causing tissue damage. These inflammatory responses have been reported to activate the release of various proinflammatory cytokines through some molecular pathways or oxidative stress (Rehman and Akash 2016). Especially high blood glucose and/or lipid levels consistently cause a mild inflammatory response. This case results in the development of insulin resistance by affecting the insulin mechanism pathways. After the development of insulin resistance, tissue damage and $\beta$-cell dysfunction may develop due to oxidative stress and altered insulin sensitivity of the cells. Proinflammatory cytokines and oxidative stress are very important in the development of T2DM and insulin resistance (Akash et al. 2012; Akash et al. 2013). Proinflammatory factors such as TNF- $\alpha$ and IL-1 have been reported to contribute significantly to the development of T2DM (Akash et al. 2012; Swaroop et al. 2012). In this experimental study, which was planned based on the idea that diabetes and diabetic symptoms can be reduced by specifically suppressing these proinflammatory cytokines with etanercept and/or anakinra, histopathological findings in various tissues and organs were evaluated.

When the histopathological findings of the pancreas were evaluated in our study (HE and AF stain), pathological findings such as atrophy in Langerhans islets, degeneration, and necrosis in $\beta$-cells were found to be decreased in the treatment groups (DA, DE, DAE) $(P<0.05$, Table 2$)$. In experimental diabetes induced by STZ, an acute period between 8 days and 3 weeks has been reported (Mulder et al. 1996). The number of studies that can be evaluated as acute is quite limited. It can be said that the pancreatic findings of previous studies observed in diabetes groups in the acute period are consistent with the findings of our study (Sahin et al. 2007; Ozdemir et al. 2009). In our study, in the group where the diabetes model was created with STZ application following a high-fat diet, it was thought that a decrease in insulin synthesis and an increase in blood glucose level were formed after degeneration and necrosis in $\beta$-cells due to inflammation. As a result of increased oxidative stress and inflammatory response due to hyperglycaemia and hyperlipidaemia, it can be said that the increased release of proinflammatory cytokines may exacerbate this situation. A study in mice reported that the use of etanercept and/or anakinra improved insulin secretion and metabolic status by suppressing TNF- $\alpha$ and IL-1 cytokines that cause dysfunction in $\beta$-cells (McCall et al. 2012). In another study in 20 patients with T2DM, the administration of etanercept at a dose of $25 \mathrm{mg} / \mathrm{kg}$ twice a week (4 weeks), it has been reported that it may be effective in the recovery of $\beta$-cell functions and insulin synthesis by suppressing inflammation in the acute period (Dominguez et al. 2005). Another study determined that the blockade of IL-1 with anakinra improves hyperglycaemia, systemic inflammation markers, and $\beta$-cell functions (Larsen et al. 2007).

In accordance with these studies, it was concluded in our study that the use of anakinra and etanercept significantly reduced diabetes-related damage to $\beta$-cells in the acute phase. It can be interpreted that this is achieved by reducing inflammation, oxidative stress, and improving $\beta$-cell functions by blocking specific IL-1 and TNF- $\alpha$. It was also thought that reducing insulin resistance and systemic inflammation also contributed to this situation with the suppression of these cytokines, which increase in parallel with the increase in hyperglycaemia and the amount of free fatty acids in the blood. Thus, it was determined that as a result of the reduction of insulin resistance, systemic and local inflammation, and oxidative damage, the histological appearance of the pancreas improved, and dysfunction in $\beta$-cells was prevented. It was thought that it would be better to determine the effect of bidirectional cytokine blockade together with not only histopathological but also other metabolic and molecular markers although the co-administration of anakinra and etanercept did not make a significant difference compared to other treatment groups. Similarly, a study using etanercept and anakinra together reported that it could improve insulin and blood sugar levels in Type 2 diabetic rats and that etanercept was more effective in increasing insulin (Dik et al. 2018). 
Hydropic and/or vacuolar degeneration, necrosis, and dissociation in the hepatocytes, and enlargement of sinusoids were detected in the D group. Evident limited fat vacuoles were detected in some hepatocytes. These findings overlap with other experimental studies (Sahin et al. 2007; Ozdemir et al. 2009; Adeyi et al. 2012; Aboonabi et al. 2014). These degenerative changes in hepatocytes can be evaluated as a result of increased oxidative stress and mitochondrial dysfunction after hyperglycaemia. Hyperglycaemia reduces antioxidant activity by suppressing glutathione reductase and superoxide dismutase enzymes, and it has been reported that it triggers oxidative stress with the increase of glycation products (West 2000). On the other hand, it has been determined to cause oxidative stress by increasing the level of malondialdehyde due to lipid peroxidation of a high-fat diet and decreasing the total antioxidant capacity (Yang et al. 2006). In contrast, it has been reported that oxidative stress is reduced by suppressing proinflammatory cytokines such as TNF- $\alpha$ and IL-1 (Gorogawa et al. 2002). In the current study, it was noted that diabetes-induced liver damage was significantly reduced in the DA, DE, and DAE groups $(P<0.05)$. It was thought that this situation may have occurred as a result of the reduction of oxidative stress by specifically antagonizing IL- 1 and TNF- $\alpha$.

It was observed that histopathological lesions in the kidneys were mostly in the epithelium of the tubules. Hydropic degeneration observed in tubules epithelium in the D group decreased in the anakinra and etanercept applied groups was determined. It was thought that these degenerative changes were caused by increased oxidative stress and proinflammatory cytokines in the T2DM process. Indeed, it has been reported that cytokines such as TNF- $\alpha$, IL-1, and IFN-c play an important role in the mechanism of histological damage caused by oxidative stress in the liver and kidneys (Sugano et al. 2006; Aboonabi et al. 2014). Therefore, it can be concluded that tubular degeneration decreased in the treatment groups with the specific suppression of TNF- $\alpha$ and IL-1 pro-inflammatory. In our study, findings such as mesangial hypertrophy, glomerulosclerosis, and thickening of the basement membrane were not observed in the glomeruli. In previous experimental diabetes studies, contrary to the findings in this study, such glomerular lesions were reported. Also, a narrowing in the Bowman's space was reported (Phillips et al. 2001; Sugano et al. 2006; Aboonabi et al. 2014). However, the common feature of the findings in these studies is that they are chronic stage diabetes findings. It can be interpreted that the slight enlargement of the Bowman's space in the study is an acute phase finding. As a matter of fact, in a study examining the findings of acute period diabetes, it was reported that enlargement may occur as a result of fluid leakage into the Bowman's space due to increased permeability and glomerular function as a result of vascular damage occurring (Ozdemir et al. 2009).

It was noted that the degenerative changes observed in tubules seminiferous of the testicular in D group decreased significantly in the DA, DE, and DAE groups $(P<0.05)$. These lesions in the $\mathrm{D}$ group coincide with the findings observed in other experimental studies (Guneli et al. 2008; Ghanbari et al. 2016; Long et al. 2018). Diabetes causes increased oxidative stress in the male reproductive system. During diabetes, the balance between ROS production and deoxidation is disturbed. ROS produced in excess can disrupt the normal structure of cells, including proteins and DNA, and thus it can damage cellular function (Maedler et al. 2009). The most important damage of oxidative stress caused by diabetes is vasculopathy causing diabetic microvascular complications (Long et al. 2018). In addition, cytokines such as IL-1 $\beta$, IL-1 $\alpha$, IL-6, TNF- $\alpha$ have been reported to have negative effects on germ cells in acute testicular inflammation experiments (Guazzone et al. 2009). In our study, it can be interpreted that the oxidative stress that increased as a result of diabetes and the proinflammatory cytokine synthesis and inflammation triggered by it were reduced by the suppression of IL-1 and TNF- $\alpha$ (anakinra and etanercept), thus preventing testicular degeneration. 
In our study, a significant loss of body weight was observed in animals with diabetes $(P<0.005)$, and this was thought to be caused by increased muscle loss and loss of tissue proteins in animals with diabetes, as reported in previous studies (Cheng et al. 2013; Jain 2015). Also, it has been noted that kidney weight and relative kidney weight are higher in diabetic groups, as reported in the literature (Zafar and Naqvi 2010; Eleazu et al. 2013). Although the decrease in weight loss due to diabetes, increase in kidney weight and relative kidney weight continued in the DA group treated with anakinra, it was noted that it decreased in the DE group treated with etanercept. This has been interpreted as etanercept may prevent diabetes-induced renal hypertrophy, muscle and protein loss.

In conclusion, it was determined that the single or combined use of anakinra and etanercept at the doses applied in the study to specifically antagonize IL-1 and TNF- $\alpha$ to T2DM rats did not have any toxic-pathological effects. In the study, it was revealed that with this treatment applied to rats with T2DM, damage to the tissues examined in the acute period significantly decreased. Suppression of proinflammatory cytokines may be a good treatment strategy since inflammation affects the pathogenesis and complications of T2DM. The effects of single or combined use of anakinra and etanercept should be evaluated not only histopathologically but also with metabolic and molecular markers.

\section{Conflict of Interest}

The authors declare that they have no conflict of interest.

\section{References}

Aboonabi A, Rahmat A, Othman F 2014: Effect of pomegranate on histopathology of liver and kidney on generated oxidative stress diabetic induced rats. J Cytol Histol 6: 2-5

Adeyi AO, Idowu BA, Mafiana CF, Oluwalana SA, Ajayi OL, Akinloye OA 2012: Rat model of food-induced non-obese-type 2 diabetes mellitus: comparative pathophysiology and histopathology. Int $\mathrm{J}$ Physiol Pathophysiol Pharmacol 4: 51

Akash MSH, Shen Q, Rehman K, Chen S 2012: Interleukin-1 receptor antagonist: a new therapy for type 2 diabetes mellitus. J Pharm Sci 101: 1647-1658

Akash MSH, Rehman K, Chen S 2013: Role of inflammatory mechanisms in pathogenesis of type 2 diabetes mellitus. J Cell Biochem 114: 525-531

Bonilla E, Lee Y, Phillips P, Perl A 2007: Hypoglycaemia after initiation of treatment with etanercept in a patient with type 2 diabetes mellitus. Ann Rheum Dis 66: 1688

Chawla A, Chawla R, Jaggi S 2016: Microvasular and macrovascular complications in diabetes mellitus: distinct or continuum? Indian J Endocrinol Metab 20: 546

Cheng D, Liang B, Li Y 2013: Antihyperglycemic effect of Ginkgo biloba extract in streptozotocin-induced diabetes in rats. BioMed Res Int: ID 162724, 7 p.

Dik B, Bahcivan E, Eser Faki H, Uney K 2018: Combined treatment with interleukin-1 and tumor necrosis factoralpha antagonists improve type 2 diabetes in rats. Can J Physiol Pharmacol 96: 751-756

Dogrul A, Gul H, Yesilyurt O, Ulas UH, Yildiz O 2011: Systemic and spinal administration of etanercept, a tumor necrosis factor alpha inhibitor, blocks tactile allodynia in diabetic mice. Acta Diabetol 48: 135-142

Dominguez H, Storgaard H, Rask-Madsen C, Hermann TS, Ihlemann N, Nielsen DB, Spohr C, Kober L, Vaag A, Torp-Pedersen C 2005: Metabolic and vascular effects of tumor necrosis factor- $\alpha$ blockade with etanercept in obese patients with type 2 diabetes. J Vasc Res 42: 517-525

Donath MY, Shoelson SE 2011: Type 2 diabetes as an inflammatory disease. Nat Rev Immunol 11: 98-107

Ehses JA, Perren A, Eppler E, Ribaux P, Pospisilik JA, Maor-Cahn R, Gueripel X, Ellingsgaard H, Schneider MK, Biollaz G 2007: Increased number of islet-associated macrophages in type 2 diabetes. Diabetes 56: 2356-2370

Ehses JA, Lacraz G, Giroix MH, Schmidlin F, Coulaud J, Kassis N, Irminger JC, Kergoat M, Portha B, HomoDelarche F, Donath MY 2009: IL-1 antagonism reduces hyperglycemia and tissue inflammation in the type 2 diabetic GK rat. Proc Natl Acad Sci USA 106: 13998-14003

Eleazu C, Iroaganachi M, Eleazu K 2013: Ameliorative potentials of cocoyam (Colocasia esculenta L.) and unripe plantain (Musa paradisiacal L.) on renal and liver growth in streptozotocin induced diabetic rats. J Acute Dis 2: 140-147

Ghanbari E, Nejati V, Khazaei M 2016: Antioxidant and protective effects of Royal jelly on histopathological changes in testis of diabetic rats. Int J Reprod Med 14: 519-526

Gopalakrishnan S, Geetha A 2017: Study on the impact of family history of diabetes among type 2 diabetes mellitus patients in an urban area of Kancheepuram district, Tamil Nadu. Int J Community Med Public Heal 4: $4151-4156$ 
Gorogawa S-i, Kajimoto Y, Umayahara Y, Kaneto H, Watada H, Kuroda A, Kawamori D, Yasuda T, Matsuhisa M, Yamasaki Y 2002: Probucol preserves pancreatic $\beta$-cell function through reduction of oxidative stress in type 2 diabetes. Diabetes Res Clin Pract 57: 1-10

Guazzone VA, Jacobo P, Theas MS, Lustig L 2009: Cytokines and chemokines in testicular inflammation: a brief review. Microsc Res Tech 72: 620-628

Guneli E, Tugyan K, Ozturk H, Gumustekin M, Cilaker S, Uysal N 2008: Effect of melatonin on testicular damage in streptozotocin-induced diabetes rats. Eur Surg Res 40: 354-360

Harford KA, Reynolds CM, McGillicuddy FC, Roche HM 2011: Fats, inflammation and insulin resistance: insights to the role of macrophage and T-cell accumulation in adipose tissue. Proc Nutr Soc 70: 408-417

Jain MD 2015: Silibinin, a bioactive flavanone, prevents the progression of early diabetic nephropathy in experimental type-2 diabetic rats. Int J Green Pharm 9: 118-124

Keane KN, Calton EK, Carlessi R, Hart PH, Newsholme P 2017: The bioenergetics of inflammation: insights into obesity and type 2 diabetes. Eur J Clin Nutr 71: 904-912

Kim B, Lee Y, Kim E, Kwak A, Ryoo S, Bae S, Azam T, Kim S, Dinarello CA 2013: The interleukin-1 $\alpha$ precursor is biologically active and is likely a key alarmin in the IL-1 family of cytokines. Front Immunol 4: 391

Larsen CM, Faulenbach M, Vaag A, Vølund A, Ehses JA, Seifert B, Mandrup-Poulsen T, Donath MY 2007 : Interleukin-1-receptor antagonist in type 2 diabetes mellitus. N Engl J Med 356: 1517-1526

Long L, Qiu H, Cai B, Chen N, Lu X, Zheng S, Ye X, Li Y 2018: Hyperglycemia induced testicular damage in type 2 diabetes mellitus rats exhibiting microcirculation impairments associated with vascular endothelial growth factor decreased via PI3K/Akt pathway. Oncotarget 9: 5321-5336

Luna L 1968: Routine staining procedures. Manual of histologic staining methods of the Armed Forces Institute of Pathology. Blakiston Division McGraw-Hill, New York, 258 p.

Maedler K, Dharmadhikari G, Schumann DM, Størling J 2009: Interleukin-1 beta targeted therapy for type 2 diabetes. Expert Opin Biol Ther 9: 1177-1188

McCall M, Pawlick R, Kin T, Shapiro A 2012: Anakinra potentiates the protective effects of etanercept in transplantation of marginal mass human islets in immunodeficient mice. Am J Transplant 12: 322-329

Mirmiran P, Bahadoran Z, Azizi F 2014: Functional foods-based diet as a novel dietary approach for management of type 2 diabetes and its complications: A review. World J Diabetes 5: 267-281

Mulder H, Ahrén B, Sundler F 1996: Islet amyloid polypeptide (amylin) and insulin are differentially expressed in chronic diabetes induced by streptozotocin in rats. Diabetologia 39: 649-657

Ozdemir O, Akalin PP, Baspinar N, Hatipoglu F 2009: Pathological changes in the acute phase of streptozotocininduced diabetic rats. Bull Vet Inst Pulawy 53: 783-790

Phillips AO, Baboolal K, Riley S, Gröne H, Janssen U, Steadman R, Williams J, Floege J 2001: Association of prolonged hyperglycemia with glomerular hypertrophy and renal basement membrane thickening in the Goto Kakizaki model of non-insulin-dependent diabetes mellitus. Am J Kidney Dis 37: 400-410

Rehman K, Akash MSH 2016: Mechanisms of inflammatory responses and development of insulin resistance: how are they interlinked? J Biomed Sci 23: 1-18

Sahin K, Onderci M, Tuzcu M, Ustundag B, Cikim G, Ozercan İH, Sriramoju V, Juturu V, Komorowski JR 2007: Effect of chromium on carbohydrate and lipid metabolism in a rat model of type 2 diabetes mellitus: the fat-fed, streptozotocin-treated rat. Metabolism 56: 1233-1240

Srinivasan K Viswanad B, Asrat L, Kaul CL, Ramarao P 2005: Combination of high-fat diet-fed and low-dose streptozotocin-treated rat: a model for type 2 diabetes and pharmacological screening. Pharmacol Res 2: 313-320

Stanley TL, Zanni MV, Johnsen S, Rasheed S, Makimura H, Lee H, Khor VK, Ahima RS, Grinspoon SK 2011: TNF- $\alpha$ antagonism with etanercept decreases glucose and increases the proportion of high molecular weight adiponectin in obese subjects with features of the metabolic syndrome. J Clin Endocrinol Metab 96: 146-150

Sugano M, Yamato H, Hayashi T, Ochiai H, Kakuchi J, Goto S, Nishijima F, Lino N, Kazama JJ, Takeuchi T 2006: High-fat diet in low-dose-streptozotocin-treated heminephrectomized rats induces all features of human type 2 diabetic nephropathy: a new rat model of diabetic nephropathy. Nutr Metab Cardiovasc Dis 16: 477-484

Swaroop JJ, Rajarajeswari D, Naidu J 2012: Association of TNF- $\alpha$ with insulin resistance in type 2 diabetes mellitus. Indian J Med Res 135: 127-130

Trayhurn P, Wood I 2005: Signalling role of adipose tissue: adipokines and inflammation in obesity. Biochem Soc Trans 33: 1078-81.

Vardı N, Iraz M, Öztürk F, Uçar M, Gül M, Eşrefoğlu M, Otlu A 2005: Improving effects of melatonin on the histologic alterations of rat kidneys induced by experimental diabetes. J Inonu Univ Med Fac 12: 145-152

Wellen KE, Hotamisligil GS 2005: Inflammation, stress, and diabetes. J Clin Investig 115: 1111-1119

West IC 2000: Radicals and oxidative stress in diabetes. Diabet Med 17: 171-180

Yang R, Le G, Li A, Zheng J, Shi Y 2006: Effect of antioxidant capacity on blood lipid metabolism and lipoprotein lipase activity of rats fed a high-fat diet. Nutrition 22: 1185-1191

Zafar M, Naqvi SN-u-H 2010: Effects of STZ-induced diabetes on the relative weights of kidney, liver and pancreas in albino rats: a comparative study. Int J Morphol 28: 135-142 
Plate XIII

Ozdemir O. et al.: The effect ... pp. 421-429

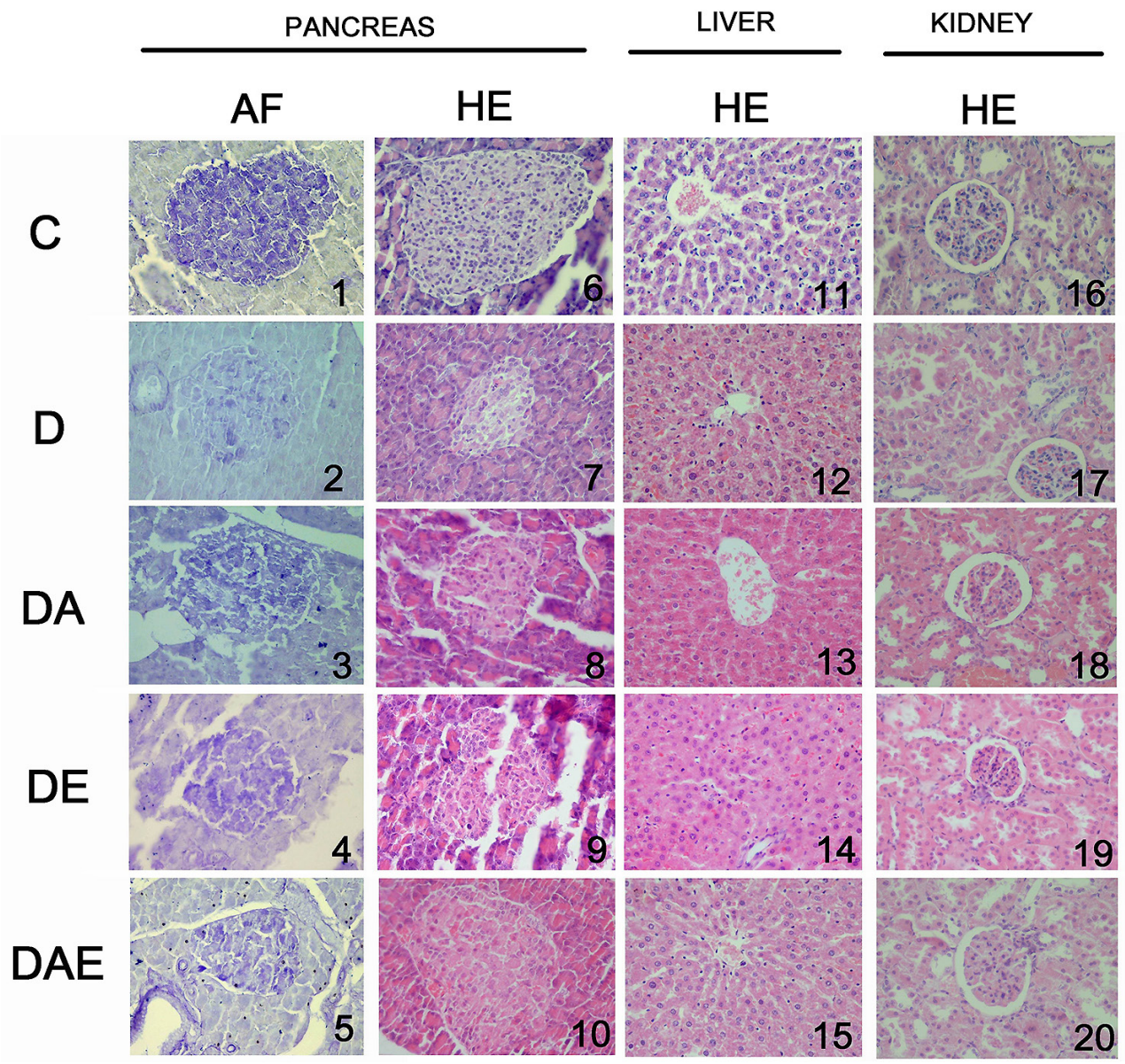

Fig. 3. Histopathological changes in groups. 1-10: The appearance of $\beta$-cells in Langerhans islets in the pancreas (1-5 aldehyde fuchsin, 6-10 haematoxylin-eosin). 11-15: Degenerative changes in hepatocytes in the liver were evident in the diabetes group, while a decrease was noted in the treatment groups. 16-20: Tubular degeneration in the kidneys shows a significant increase in the diabetes group, while the other groups appear similar to the control. Increase in Bowman spaces was evident in diabetes groups. (1-5 aldehyde fuchsin, 6-20 haematoxylin-eosin). $\mathrm{C}$ - control; D - diabetes; DA - diabetes + anakinra; DE - diabetes + etanercept; DAE - diabetes + anakinra + etanercept 